OPEN

SUBJECT AREAS:

ICHTHYOLOGY

PALAEOECOLOGY

BIOMECHANICS

PALAEONTOLOGY

Received

26 September 2012

Accepted

29 November 2012

Published

20 December 2012

Correspondence and requests for materials should be addressed to

J.R.G. (jgrubich@ aucegypt.edu)

\section{Mega-Bites: Extreme jaw forces of living and extinct piranhas (Serrasalmidae)}

\author{
Justin R. Grubich ${ }^{1,2,3}$, Steve Huskey ${ }^{3}$, Stephanie Crofts ${ }^{4}$, Guillermo Orti ${ }^{5}$ \& Jorge Porto ${ }^{6}$
}

'Department of Biology American University in Cairo, New Cairo, Egypt 1 1835, ${ }^{2}$ Division of Fishes The Field Museum of Natural History, Chicago, IL 60605, ${ }^{3}$ Biology Department Western Kentucky University, Bowling Green, KY $42101,{ }^{4}$ Department of Biology, University of Washington, Seattle, WA 98195, ${ }^{5}$ Department of Biological Sciences, George Washington University, Washington, DC 20052, Instituto Nacional de Pesquisas da Amazônia (INPA) Manaus-AM, Brazil 6901 1-970.

Here, we document in-vivo bite forces recorded from wild piranhas. Integrating this empirical data with allometry, bite simulations, and FEA, we have reconstructed the bite capabilities and potential feeding ecology of the extinct giant Miocene piranha, Megapiranha paranensis. An anterior bite force of $320 \mathrm{~N}$ from the black piranha, Serrasalmus rhombeus, is the strongest bite force recorded for any bony fish to date. Results indicate $M$. paranensis' bite force conservatively ranged from 1240-4749 N and reveal its novel dentition was capable of resisting high bite stresses and crushing vertebrate bone. Comparisons of body size-scaled bite forces to other apex predators reveal $S$. rhombeus and $M$. paranensis have among the most powerful bites estimated in carnivorous vertebrates. Our results functionally demonstrate the extraordinary bite of serrasalmid piranhas and provide a mechanistic rationale for their predatory dominance among past and present Amazonian ichthyofaunas.

T he evolution of gnathostome jaws, along with bite forces that can capture and masticate active prey is a key functional innovation underlying the diversification of early Devonian vertebrates ${ }^{1}$. As a result of their fundamental importance in expanding predatory niches and promoting the success of vertebrates, jaws and bite forces in living and extinct species have been repeatedly modeled through lever and linkage mechanics, bite simulations, and 3-D finite element analyses (FEA $)^{2-6}$. However, few theoretical studies have validated their models with empirical measurements from living taxa ${ }^{7-9}$.

In-vivo experiments in the field to elicit and record ecologically realistic biting behaviors for predatory species are rare, dangerous, and difficult to perform ${ }^{10}$. Among bony fishes, piranhas (Serrasalmidae) represent an ideal group of predatory vertebrates in which to investigate the evolution of extreme biting capabilities because of their aggressive nature, relatively small size, and accessible populations. While anecdotes of piranha-infested waters skeletonizing hapless victims are generally hyperbole, the effectiveness of their bite is not. Even at their small body sizes, diet studies indicate that piranhas will attack and bite chunks out of prey many times larger than themselves ${ }^{11-13}$.

Recent molecular evidence indicates there are three major subclades of the Serrasalmidae: 1) the carnivorous piranha-clade, 2) the omnivorous Myleus-clade, and 3) the herbivorous pacu-clade ${ }^{14}$. Within the piranha-clade, feeding ecology varies from the typical flesh and fin eating forms of Serrasalmus and Pygocentrus spp., to the highly specialized lepidophagous (i.e. scale-eating) Catoprion mento. Tooth shape and dentition patterns in Serrasalmidae demonstrate a strong functional relationship to diet $^{11-13}$. Carnivorous piranhas typically have jaws lined with a single row of 6-7 serrated, multi-cusped, triangular, blade-like teeth. Dentition and tooth morphology have long been used to classify serrasalmid species ${ }^{15,16}$. In 2009, Cione et al. ${ }^{17}$ described a new extinct serrasalmid species of the Upper Miocene from the Paraná geological formation in Argentina. Megapiranha paranensis is classified as a new genus of a giant, piranha-like species described from a single fossilized premaxilla jaw bone fragment that had a set of three triangular teeth set in a zig-zag pattern. The fossil teeth are also morphologically distinct. They have labio-lingually compressed pointed cusps with finely serrated cutting edges similar to a shark. In contrast, the mid tooth expands into a broad lingual shelf that is anchored to the jaw with a robust circular base (Fig. 1, inset). These morphological synapomorphies with extant serrasalmid species place M. paranensis as sister taxa to the carnivorous "piranha-clade" and a more distant intermediate relative to the herbivorous "pacu-clade" (SI Fig. 1).

The dentition pattern and tooth shape of the $M$. paranensis fossil indicates an intermediate morphology capable of both slicing soft flesh and crushing hard prey. However, the diet of this giant piranha species still remains a mystery. The Miocene epoch is renowned for its gigantism in Neotropical aquatic flora and 


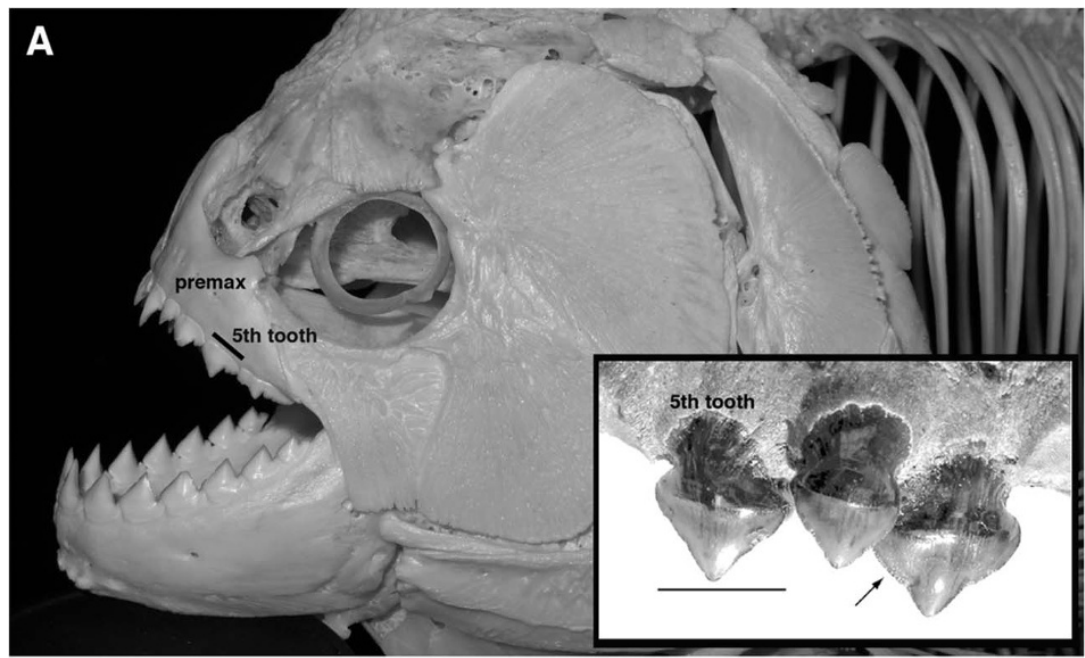

B

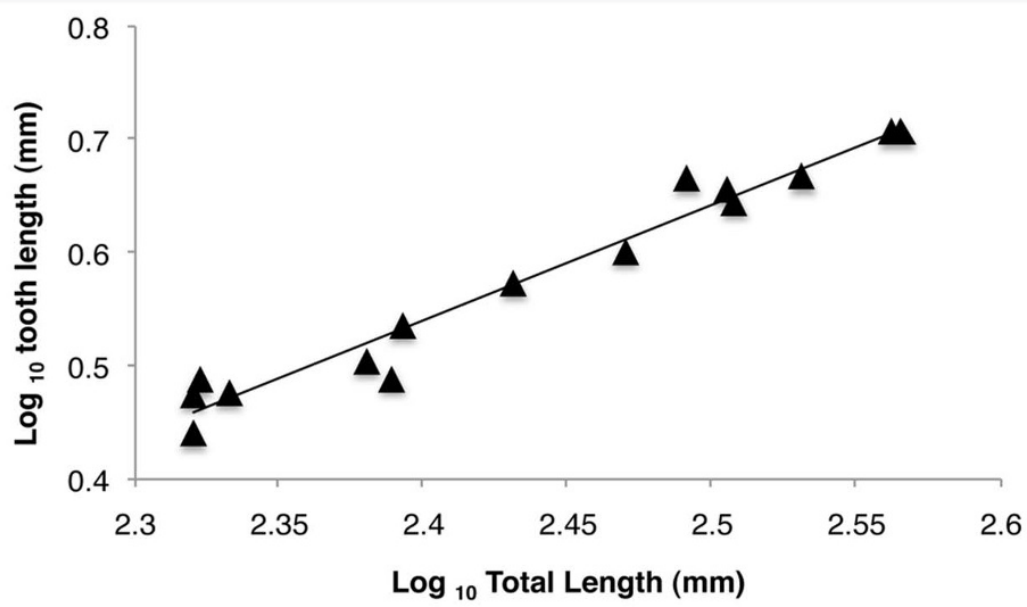

Figure 1 Skull anatomy of S. rhombeus (photo by SH) and fossil teeth of $M$. paranensis (inset, reprinted from Cione et al.). Teeth of S. rhombeus and M. paranensis share similarly shaped cusps that form labio-lingually compressed triangular blades. Arrow (inset) demarks fine serrations on $M$. paranensis tooth for slicing flesh. Homologous landmarks were measured as length of labial base $(\mathrm{mm})$ for the $5^{\text {th }}$ premaxillary tooth (A). Allometric relationship describing growth of the $5^{\text {th }}$ tooth relative to body size, measured as total length $(\mathrm{mm})$ in the black piranha, S. rhombeus (B). Tooth length scales isometrically with increasing body size (slope $=1.02)$. Data were $\log _{10}$ transformed and fitted to a least-squares linear regression model: $\log _{10}($ tooth $)=$ $1.02 \log _{10}(T L)-1.91\left(r^{2}=0.96, F_{(1,14)}=339.8 ; p<0.0001\right)$. Using this regression equation, a conservative body size of $71 \mathrm{~cm}$ TL was back-calculated for M. paranensis and was subsequently used to estimate its lower bound of bite forces (Fig. 2A).

fauna $^{18,19}$. Thus, it is reasonable to assume the food resources available to Megapiranha would likely have required jaw forces and dental weaponry capable of capturing and processing very large prey.

Here we report the first in-vivo bite forces recorded from wild specimens of the largest species of carnivorous piranha, Serrasalmus rhombeus, and describe the underlying functional morphology of the jaws that power their bite. Using this extant species as an allometric surrogate, we are able to infer the feeding ecology of the giant Miocene piranha, M. paranensis, by reconstructing its bite forces and the mechanical capabilities of its unique dentition. Lastly, by removing the effects of body size, we are able to demonstrate that the biting abilities of these relatively diminutive serrasalmid fishes have biomechanically surpassed much larger iconic predators documented in the literature.

\section{Results}

In-vivo bite forces. Maximum bite force was tested in-vivo for 15 specimens of Serrasalmus rhombeus ranging in body length from 205 to $368 \mathrm{~mm}$ TL using a customized force gauge (SI Table 1). Bite force varied nearly five-fold from $67 \mathrm{~N}$ in a $0.17 \mathrm{~kg}$ individual to more than $320 \mathrm{~N}$ for a $1.1 \mathrm{~kg}$ specimen. To examine the ontogeny of bite performance in $S$. rhombeus, we plotted bite force against body size (Fig. 2A). In-vivo bite forces in S. rhombeus scale with significant positive allometry (slope $=2.30$ ) demonstrating that jaw strength increases considerably faster than body length.

Jaw functional morphology. Dissections of S. rhombeus' jaws reveal their powerful bite is generated by a massive adductor mandibulae muscle complex. It is made up of four distinct subdivisions: A1, A2 lateral, A2 medial, A3 (Fig. 2B, C). The A1 subdivision is a smaller fusiform muscle that originates on the ventral portion of the preopercle and extends dorso-rostrally to wrap around the coronoid process of the articular and insert onto the dorso-medial surface of the dentary. The two large A2 subdivisions span out and fill the entire suspensorium to make up more than $80 \%$ of the adductor mandibulae mass. Together the A2 subdivisions along with the medial A3 fuse into a thick rope-like tendon that inserts supra-distally into a deep Mecklian fossa on the medial lower jaw (Fig. 2C). 
A
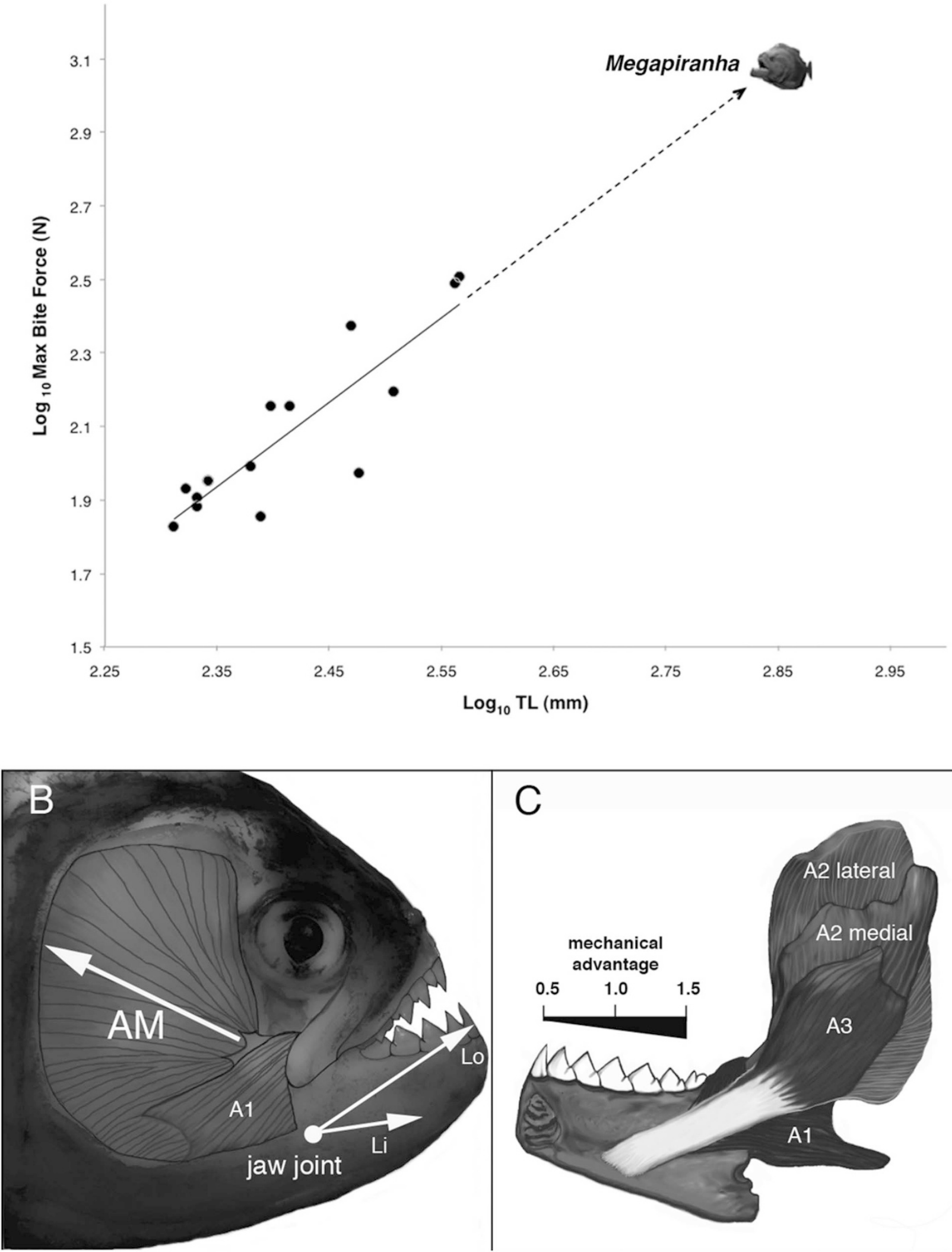

Figure 2 Scaling of maximum in-vivo bite forces (N) plotted against body size (TL) for Serrasalmus rhombeus (A). Data were Log 10 transformed and fitted to least squares linear regression: $\log _{10}(N)=2.30 \log _{10}(T L)-3.469\left(r^{2}=0.77, F_{(1,14)}=43.7 ; p<0.0001\right)$. Predicted maximum bite force for a 71 $\mathrm{cm}$ TL $M$. paranensis is also plotted (dashed arrow). Jaw functional morphology revealed a massive adductor mandibulae muscle complex (AM) that rotates the lower jaw postero-dorsally (white arrow) via a robust rope-like tendon (B, C). Lower jaw mechanics depict a highly modified $3^{\text {rd }}$ class lever where the closing mechanical advantage ( $\mathrm{Li} / \mathrm{Lo}$ ) amplifies AM muscle force transmission by $50 \%$ to $150 \%$ from the jaw tip to the posterior teeth (C). 
Table 1 | Comparison of in-vivo and theoretical bite forces (BF) derived from adductor mandibulae (AM) physiology and lower jaw morphometrics for Serrasalmus rhombeus $(\mathrm{N}=6)$

\begin{tabular}{lccccccc} 
TL $(\mathrm{mm})$ & Body Mass $(\mathrm{g})$ & AM (g) & AM CSA $\left(\mathrm{cm}^{2}\right)$ & MA (jaw tip) & In Vivo Max BF (N)* & Anterior BF (N)* & Mid-Jaw BF (N) \\
\hline 365 & 1130 & 24.7 & 21.0 & 0.51 & 306.93 & 311.3 & 631.2 \\
368 & 1120 & 26.5 & 23.5 & 0.46 & 320.27 & 287.6 & 559.7 \\
295 & 600 & 14.5 & 14.1 & 0.47 & 235.76 & 156.9 & 269.7 \\
322 & 850 & 18.9 & 18.2 & 0.51 & 155.69 & 218.4 & 402.3 \\
210 & 220 & 5.7 & 7.7 & 0.48 & 84.51 & 72.3 & 123.6 \\
240 & 280 & 6.3 & 6.9 & 0.47 & 97.86 & 76.2 & 139.7 \\
\hline
\end{tabular}

"BF not significantly different: ANCOVA (t-ratio $d f=2,11=0.65, \mathrm{p}=0.531$ ).

The mechanical advantage (MA) of the lower jaw in vertebrates determines the proportion of adductor muscle force that is transmitted to the bite and is a function of the ratio of the in-lever length $(\mathrm{Li}=$ the distance from the jaw joint to where the adductor muscles insert onto the mandible) to the out-lever length ( $\mathrm{Lo}=$ the distance from the jaw joint to the distal-most tooth tip). In Serrasalmus rhombeus, the extreme anterior insertion of the A2/A3 tendon creates a high mechanical advantage for even the most rostral teeth $(\mathrm{MA} \sim 0.5)$ (Fig. 2C, Table 1). For practical comparison, if the prey is bitten farther back along the lower jaw at the $4^{\text {th }}$ tooth position, the shorter Lo increases the MA to 1.0 and approaches 1.5 at the most posterior teeth.

To investigate the effects of having a massive adductor mandibulae complex in combination with a high MA on piranha bite force, we ran a $2 \mathrm{D}$ computer simulation that uses jaw morphometrics and adductor muscle physiology parameters to predict bite forces in six individual $S$. rhombeus covering a range of body size. As expected from the jaw lever mechanics, simulation results demonstrate bite force nearly doubles from the anterior most teeth to the mid-jaw position (Table 1). For one of our largest specimens ( $\mathrm{TL}=$ $365 \mathrm{~mm}$ ), predicted mid-jaw bite force (where MA $=1.0$ ) was calculated to be as high as $631 \mathrm{~N}$, more than twice the in-vivo bite force recorded for this individual. However, an analysis of covariance comparing simulation results with our empirical data revealed the predicted anterior bite forces derived from jaw morphometrics are not significantly different from the maximum in-vivo bite forces recorded for these specimens (Table 1).

Body size and bite force reconstruction. Estimates for Megapiranha paranensis were back-calculated from allometric relationships of tooth growth and in-vivo bite force for S. rhombeus. In contrast to previously published estimates $(\sim 73 \mathrm{~kg}, 128 \mathrm{~cm} \mathrm{TL})^{17}$, our allometric analysis of $M$. paranensis' fossil premaxilla suggests a more conservative body size: $\sim 10 \mathrm{~kg}, 71 \mathrm{~cm}$ TL (Fig. 1B). Bite force predictions for $M$. paranensis using our calculated body size and the previous published estimate ranged from 1240 to $4749 \mathrm{~N}$, respectively, at least a 4 -fold increase in bite force over the largest S. rhombeus (Fig. 2A).

Bite simulations and fea of fossil teeth. Bite simulations using a bronze-alloy metal replica of the $M$. paranensis jaw fossil were conducted to examine the potential for comminution of bony materials. These indentation trials tested the fossil teeth's ability to penetrate ecologically relevant bony prey of varying thickness. Using the predicted bite force range (e.g. 1245-4448 N), Megapiranha's teeth penetrated the thick cortical layer $(5.94 \mathrm{~mm})$ of a bovine femur in a primarily linear fashion generating piercing indentations from 1.0-2.3 mm deep (Fig. 3). Further simulation tests on aquatic turtle carapace and dermal scales from armored catfishes repeatedly resulted in catastrophic punctures at much lower bite forces $($ range $=66.7-889.6 \mathrm{~N}$; SI Movie 1 ).

To better understand the functional significance of the unique shape of the $M$. paranensis premaxillary tooth, we used FEA programs to simulate the predicted loads generated during biting. We applied these loads to models of the M. paranensis premaxillary teeth, as well as to homologous teeth of two closely related serrasalmid relatives that cover the spectrum of tooth shapes and feeding ecologies (Fig. 4). We examined both Von Mises stress, which acts as a predictor of the likelihood of failure, and Total Strain Energy, which predicts resistance to deformation and thus efficiency of the shape at transmitting bite forces. Using these two metrics, we examined the effects of different tooth shapes under the high loading regimes that would be experienced when biting into hard bony materials. FEA results indicate when force is applied at the cusp of the tooth, stresses are concentrated around the loading area in all three morphs. In addition, stresses are distributed across the body of the Piaractus brachypomus tooth, onto the medial face. Distribution patterns change when force is applied over the upper third of the tooth as if it were puncturing through a hard bony material. Across all tooth types, stresses are concentrated around the lowest point of loading. However, stresses are distributed through the body of the tooth in both the $P$. brachypomus and $M$. paranensis and are channeled to the base of the tooth. In contrast, stresses in the Pygocentrus nattereri tooth remain concentrated in a broad ring around the middle of the tooth. The magnitudes of Von Mises stresses and Total Strain Energy are consistently higher in the sharper $P$. nattereri and $M$. paranensis tooth morphologies compared to the blunter shape of P. brachypo$m u$ indicating a greater likelihood of structural failure and deformation while puncturing hard materials at these forces (Fig. 4; Table 2).

\section{Discussion}

An in-vivo bite force of $320 \mathrm{~N}$ in Serrasalmus rhombeus is the strongest yet recorded for any bony or cartilaginous fish to date ${ }^{7}$, and is nearly three times greater than the bite force of an equivalent size American alligator ${ }^{8}$. Positive allometry of bite force is common in carnivorous and durophagous bony and cartilaginous fishes that excise chunks of flesh or fracture hard-shelled prey by crushing ${ }^{3,20-22}$. Our analysis of wild piranhas fits this trend, and the in-vivo data demonstrate that $S$. rhombeus can bite with a force more than 30 times its weight, a remarkable feat yet unmatched among vertebrates. However, it should be noted that there was some variation in our invivo bite force data among similar sized individuals that was likely caused by some individuals under-performing due to stress or fatigue. At least one fish (TL $=310 \mathrm{~mm}$ ) appears to be an outlier in the regression depressing the slope of the relationship. Removal of this individual increases the slope to 2.48 and improves the $r$-square of the relationship to 0.85 . Thus, taking this outlier into account, the significant positive allometry of bite force presented here should be considered a conservative lower bound for maximal performance in S. rhombeus.

How do black piranhas achieve these powerful bites at such relatively small sizes? The answer stems from the extraordinary size of the adductor mandibulae complex and the efficient transmission of its large contractile forces through a highly modified jaw closing lever. Indeed, the mass of the adductor mandibulae complex makes up over $2 \%$ of S. rhombeus' total body mass. The highest percentage 


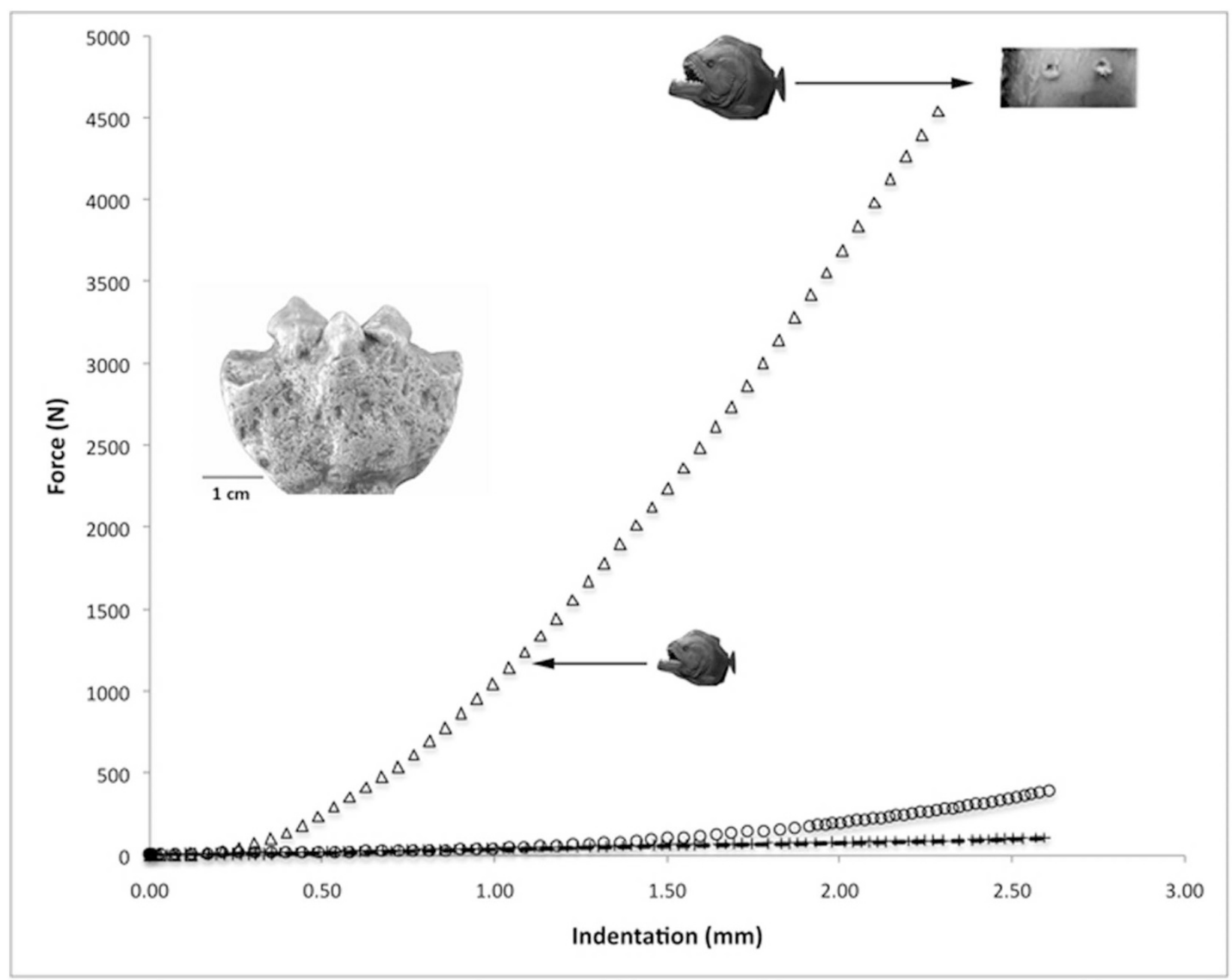

Figure 3 Bite simulation curves using a metal-alloy replica of $M$. paranensis fossil upper jaw (left inset) indenting a bovine femur $(\Delta)$, aquatic turtle carapace (O, Phrynops sp.), and dermal scales from an Amazonian armored catfish (+, Pterygoplichthys multiradiatus). Black arrows indicate the predicted anterior bite force for small and large body size estimates of $M$. paranensis. The $3^{\text {rd }}$ and $5^{\text {th }}$ teeth punctured the cortical bone layer of the bovine femur from 1.0-2.3 mm (inset upper right corner). Results from the turtle carapace and catfish dermal scales reveal Megapiranha's dentition pierces through these bony prey items at relatively low forces.

yet recorded for bony fishes ${ }^{23}$. This large muscle mass combined with a short overall muscle length results in a huge physiological cross sectional area that is directly proportional to the amount of force it can produce (Fig. 2B, Table 1). Furthermore, the extreme anterior insertion of the A2/A3 tendon gives $S$. rhombeus an anterior bite force that is powered by one of the highest jaw closing mechanical advantages ever identified in fishes (Fig. 2C, Table 1) ${ }^{24}$. Thus, unlike many actinopterygiian fishes where the closing MA of the lower jaw averages 0.27 (i.e. less than $30 \%$ of the adductor's muscle force is transmitted to the bite), S. rhombeus' lower jaw lever can harness $50 \%$ of the adductor complex's force generating capacity at the tip of its jaws. Even more impressive, if the prey is bitten on the lateral side of the jaws near the posterior teeth, this musculoskeletal arrangement further increases the jaw's closing MA to amplify the adductor complex's torque during biting by as much as $150 \%$ (Fig 2C). Our simulations results demonstrate how this underlying functional morphology amplifies the adductor muscles' force so that even the smallest specimen $(0.22 \mathrm{~kg})$ can potentially generate a range of traumatic bite forces across the jaw (e.g. 72-123 N; Table 1). The fact that our theoretical estimates for anterior bite force are statistically indistinguishable from the bite performances that were recorded near the tip of the jaws indicates the 2D model's simulation of lever mechanics combined with adductor muscle physiology accurately explains bite force capability in S. rhombeus. So, when one considers their unique jaw functional morphology combined with their aggressive biting behavior, it should come as no surprise that black piranha whether large or small can rapidly and efficiently excise large chunks out of their prey.

Although our body size estimate of $M$. paranensis is considerably smaller than previous published accounts ${ }^{17}$, it is still more than triple the maximum body size of extant $S$. rhombeus ${ }^{15}$. It is also important to note that both of these estimates fall within the range of sizes for the largest living serrasalmid, the frugivorous Tambaqui, Colossoma macropomum $^{15}$. Paleontological reconstructions using fossil evidence and inferences drawn from related extant taxa are commonly used to generate hypotheses about ecology, behavior, and biomechanics of extinct species ${ }^{2,45,25,26}$. Because of their close phylogenetic relationship, we assumed homologous jaw biomechanics, and used the ontogeny of S. rhombeus as a proxy to predict Megapiranha's bite forces. For comparison, our analysis predicts Megapiranha's bite was equivalent to the anterior bite force of a great white shark weighing over $400 \mathrm{~kg}$ (SI Table 3). Again, these bite force predictions likely underestimate Megapiranha's maximum bite force since they are based on the allometry of the variable in-vivo data. Furthermore, the in-vivo allometric relationship represents anterior bite forces and does not take into account the potential for doubling bite forces along the lower jaw. Thus, if $M$. paranensis did have similar musculoskeletal architecture in the lower jaws as in S. rhombeus (Fig. 2C) 


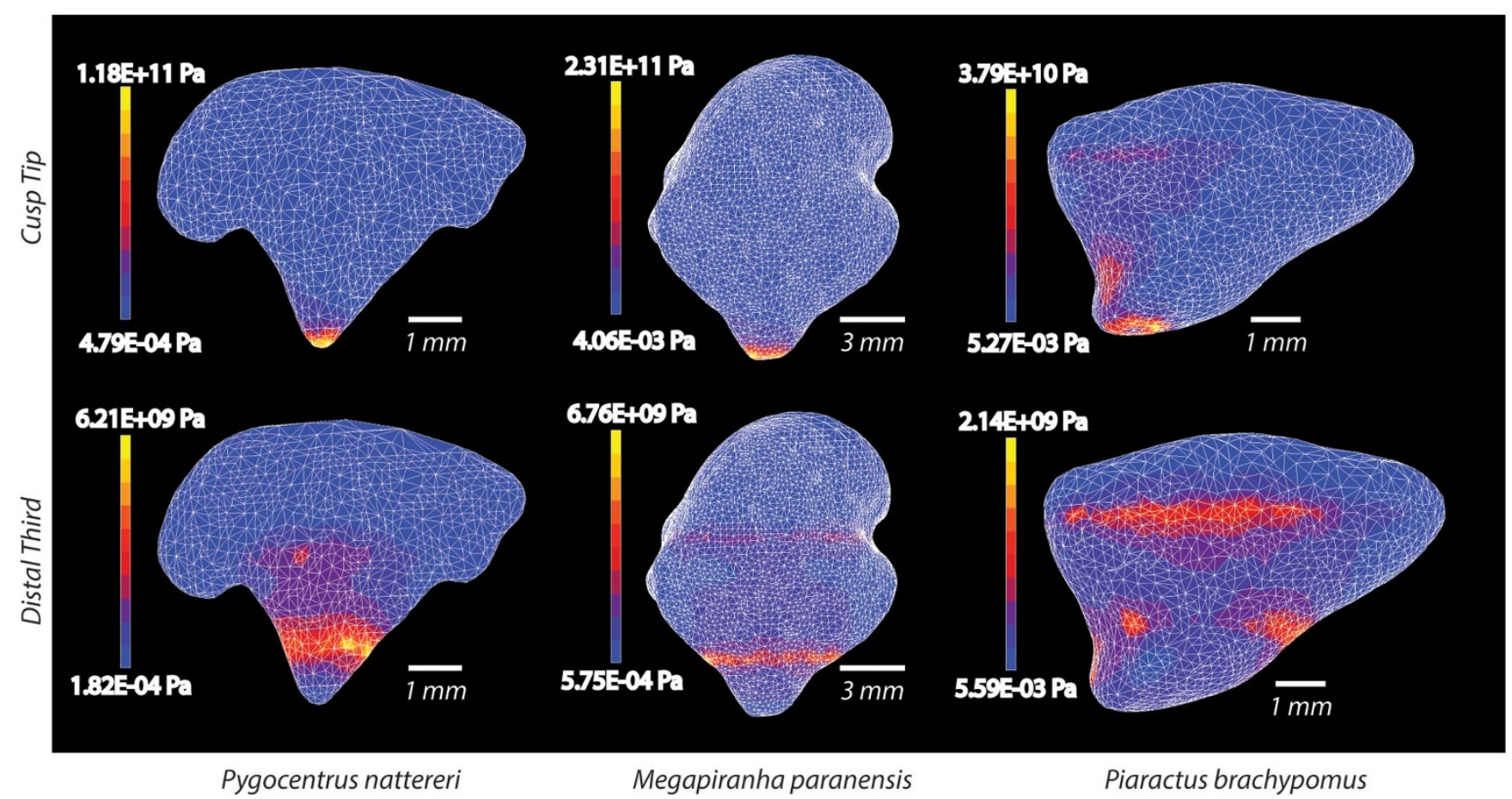

Figure 4 Finite Element Analysis of serrasalmid dentition. Maximum and minimum Von Mises stresses reported for maximum predicted bite force (scaled relative to predicted bite forces in Megapiranha); distribution of stresses remains the same regardless of magnitude of applied force. Warmer colors indicate higher concentrations of Von Mises stress and cooler colors reflect lower stress concentrations. Higher concentrations of Von Mises stress indicates a greater likelihood of failure in that region of the tooth.

but scaled up to its larger body sizes, then the mechanical advantage at its mid-jaw ( $\mathrm{MA}=1.0$ ) could have produced bite forces as high as $2480 \mathrm{~N}$ to $9498 \mathrm{~N}$. With these amplified estimates, a $73 \mathrm{~kg}$ Megapiranha's biting attack would have had the same ferocity of a $3000 \mathrm{~kg}$ great white shark (SI Table 3$)^{5}$.

What Megapiranha fed on with these powerful bites is uncertain. Tooth morphology commonly reflects feeding ability in fishes, with a strong functional relationship to diet in the Serrasalmidae ${ }^{11,16,23}$. However, the unique dentition of M. paranensis presents a paradox, exhibiting traits from relatives of both the herbivorous pacu-clade and the carnivorous piranha-clade ${ }^{14,17}$. Megapiranha teeth have robust circular bases with a broad lingual shelf that tapers into short serrated triangular blades at the crown, making them potentially suited for processing both soft and hard prey materials (Fig 2, inset). Did Megapiranha use their strong jaws and novel dentition to not only slice into their prey's compliant flesh, but also crush through their stiff bones? Our bite simulations indicate Megapiranha's hybrid teeth were indeed capable of transmitting sufficient bite pressure to generate micro-fractures in robust cortical mammalian bone as well as complete mechanical failure of thinner vertebrate bony tissues (Fig 3). For comparison, even modern carnivorous piranhas species with less robust tooth shapes are capable of some bone comminution as they often feed by taking bites out of the bony fins of fishes ${ }^{11-13}$. In fact, there are also documented cases of $S$. rhombeus biting off and consuming human phalanges ${ }^{27}$. Thus, the combination of applying the predicted bite forces from the allometry of $S$. rhombeus with the fossil replica in our penetration tests demonstrates the tooth shape of M. paranensis would have facilitated an osteophagous diet of turtles and armored catfish and to a lesser extent limb structures of larger terrestrial mammals during the Miocene Epoch.

Table 2 | Finite Element Analysis of applied forces (N) and output for serrasalmid teeth

\begin{tabular}{|c|c|c|c|c|c|c|}
\hline Species & Type of Load & Stress- Scaled (N) & $\begin{array}{c}\text { Maximum Von Mises } \\
\text { Stress (Pa) }\end{array}$ & $\begin{array}{c}\text { Minimum Von Mises } \\
\text { Stress (Pa) }\end{array}$ & Strain-Scaled (N) & $\begin{array}{c}\text { Relative Total Strain } \\
\text { Energy }(\mathrm{J})\end{array}$ \\
\hline Pygocentrus nattereri & $\begin{array}{l}\text { Cusp tip } \\
\text { Distal third }\end{array}$ & $\begin{array}{l}677.52 \\
190.937 \\
677.52 \\
190.937\end{array}$ & $\begin{array}{l}1.18 \mathrm{E}+11 \\
3.32 \mathrm{E}+10 \\
6.21 \mathrm{E}+09 \\
1.75 \mathrm{E}+09\end{array}$ & $\begin{array}{l}4.79 \mathrm{E}-04 \\
1.35 \mathrm{E}-04 \\
1.82 \mathrm{E}-04 \\
5.12 \mathrm{E}-05\end{array}$ & $\begin{array}{l}183.333 \\
51.667 \\
183.333 \\
51.667\end{array}$ & $\begin{array}{r}2.64 \mathrm{E}-03 \\
2.1 \mathrm{E}-04 \\
5.94 \mathrm{E}-04 \\
1.7 \mathrm{E}-03\end{array}$ \\
\hline Megapiranha paranensis & $\begin{array}{l}\text { Cusp tip } \\
\text { Distal Third }\end{array}$ & $\begin{array}{l}4400 * \\
1240 * \\
4400 * \\
1240 *\end{array}$ & $\begin{array}{l}2.31 \mathrm{E}+11 \\
6.52 \mathrm{E}+10 \\
6.76 \mathrm{E}+09 \\
1.91 \mathrm{E}+09\end{array}$ & $\begin{array}{l}4.06 \mathrm{E}-03 \\
1.14 \mathrm{E}-03 \\
5.75 \mathrm{E}-04 \\
1.62 \mathrm{E}-04\end{array}$ & $\begin{array}{l}4400 * \\
1240 * \\
4400 * \\
1240 *\end{array}$ & $\begin{array}{r}2.85 \mathrm{E}-01 \\
2.26 \mathrm{E}-02 \\
5.91 \mathrm{E}-02 \\
4.7 \mathrm{E}-03\end{array}$ \\
\hline Piaractus brachypomus & $\begin{array}{l}\text { Cusp tip } \\
\text { Distal Third }\end{array}$ & $\begin{array}{l}476.59 \\
134.312 \\
476.59 \\
134.312\end{array}$ & $\begin{array}{l}3.79 \mathrm{E}+10 \\
1.07 \mathrm{E}+10 \\
2.14 \mathrm{E}+09 \\
6.03 \mathrm{E}+08\end{array}$ & $\begin{array}{l}5.27 \mathrm{E}-03 \\
1.48 \mathrm{E}-03 \\
5.59 \mathrm{E}-03 \\
1.57 \mathrm{E}-03\end{array}$ & $\begin{array}{l}305.556 \\
86.111 \\
305.556 \\
86.111\end{array}$ & $\begin{array}{r}1.86 \mathrm{E}-03 \\
1.47 \mathrm{E}-04 \\
3.2 \mathrm{E}-05 \\
4.03 \mathrm{E}-04\end{array}$ \\
\hline
\end{tabular}


From the FEA models, the distribution of Von Mises stresses in the $M$. paranensis tooth revealed hybrid patterns that reflect those observed in both the sharp triangular blades of the carnivorous red belly piranha, Pygocentrus nattereri, and the blunt cuspids of the durophagous pacu, Piaractus brachypomus (Fig. 4). When loaded at the tip, both $M$. paranensis and P. nattereri exhibit Von Mises stress distributions similar to FEA models of shark teeth puncturing soft prey $^{28}$. In contrast, once the tip has presumably pierced into the bony material and compressive loading regimes are focused on the upper third of the tooth, the shape of M. paranensis distributes Von Mises stresses like the half-domed mollariform shape of P. brachypomus. The pattern reveals a reduction of Von Mises stresses in the broader sloped middle portion of the cusp where increased enameled surface area would come in contact with the bony prey material material after initial penetration (Fig. 4). The distribution patterns of Total Strain Energy (not shown) also closely mirrored the Von Mises stresses, indicating higher efficiency and lower deformation in the same region. Contrary to our initial hypothesis, the hybrid morphology of the M. paranensis tooth revealed the highest Von Mises stresses and Total Strain Energies of the three species, though the differences are slight (Table 2). This suggests that there are performance tradeoffs when combining shapes for piercing and crushing in the same tooth. However, while relative stresses and strain energies are high in $M$. paranensis, their distribution patterns reflect tensile strains, not only similar to those we found in P. brachypomus, but also seen in FEA modeling of mammalian cingulum $^{29}$. A partial cingulum in mammals creates a morphologically similar shelf that reduces tensile strains patterns in the tooth by as much as $21 \%$ after penetrating the prey. This enhanced strain resistance is apparently achieved by increasing the total surface area of the shelf that comes in contact with load. The M. paranensis tooth is apparently able to overcome these scaled shape limitations in a similar way by being absolutely larger than the teeth of either P. nattereri and P. brachypomus and expanding the surface area of the lingual slope where crushing forces would be most efficiently transmitted. Thus, the novel shape of Megapiranha's dentition appears functionally adapted to not only focus stress at the tip while puncturing flesh like the teeth of a red belly piranha, but also effectively spread impact stresses through the thicker broader base for cracking through bony materials similar to a nut- crushing pacu.

From these integrated simulations and FEA models, we surmise feeding on significantly hard prey items was at least biomechanically possible for M. paranensis. Confirmation of true osteophagous behavior on large vertebrate prey, however, still requires the discovery of Miocene fossils with bite marks that can be attributed to its dentition. Even so, our results indicate that the predicted bite pressures and hybrid tooth morphology of Megapiranha would have granted access to a vast menu of large prey resources present during the Miocene ${ }^{18}$.

The reconstructed bite forces of $M$. paranensis are impressive, but how do they compare to other vertebrate mega-predators? Using fossil evidence and indentation simulations comparable to those presented here, the bite force of Tyrannosaurus rex was estimated to be over $13,400 \mathrm{~N}^{26}$, almost three times the largest $M$. paranensis estimate. However, much of this difference is due to scaling effects attributable to T. rex's over 100 -fold greater body mass. To control for the effects of body size, we used published theoretical estimates for anterior bite force, and calculated normalized bite force quotients (BFQ's $)^{25}$ for nine living and extinct bony and cartilaginous fishes (Fig. 5; SI Table 3). These species vary widely in their phylogenetic and geological origins, but all are apex predators that feed on large prey with similar feeding strategies and powerful jaw mechanics. Correcting for body size differences reveals that both the living

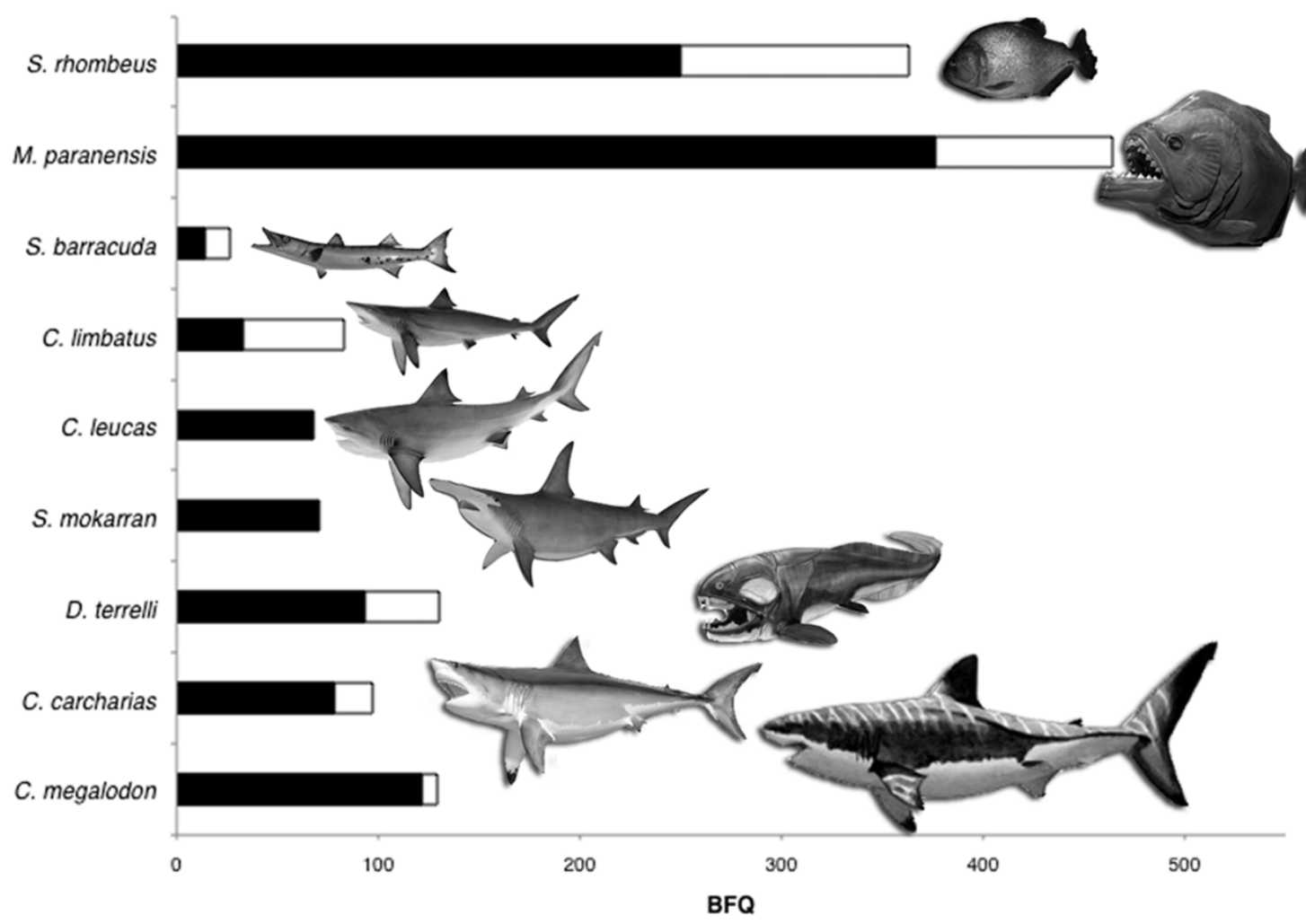

Figure $5 \mid$ Bite Force Quotients of living and extinct apex predatory fishes. Comparison of anterior bite forces among apex fish predators using calculated Bite Force Quotients (BFQ). BFQ's correct for absolute differences in bite forces attributable to drastic differences in body size by comparing mass specific residuals. Species with generally average bite strengths for their body size have a BFQ of 100. Black and white bars represent the lowest and highest quotients from small and large body size estimates, respectively. Barracuda and shark images (c) Gray Taxidermy. Dunkleosteus terrelii image () Karen Carr. 
Serrasalmus rhombeus and the extinct Megapiranha paranensis have among the most powerful bites in carnivorous fishes, living or extinct. Indeed, for its relatively diminutive size, Megapiranha paranensis' bite dwarfs other extinct mega-predators, including the enormous whale eating Carcharodon megalodon and the monstrous Devonian placoderm, Dunkleosteus terrelli.

The extreme biting abilities and jaw functional morphology of wild black piranhas presented here provide the first quantitative data that illustrate the effectiveness of their feeding mechanism. In addition, if our fossil reconstructions and simulations are correct, then Megapiranha paranensis was indeed a ferocious bone-crushing mega-predator of the Miocene epoch. Taken together with our body size corrected bite force estimates, our results for living and extinct species validate the fearsome predatory reputations of piranhas and establish this group of fishes as a pinnacle of performance in gnathostome jaw evolution.

\section{Methods}

Specimen collection. In August 2010, we collected live black piranha, Serrasalmus rhombeus (Linnaeus, 1766), while fishing along the Xingu and Iriri tributaries of the Amazon River basin near Altamira, Brazil. A total of fifteen fish ranging in body size from 205-368 mm TL were collected by hook-and-line and gill nets. To ensure minimal damage to the jaws and record maximal performance, we used barbless hooks and carried out bite force experiments as soon as possible after capture to reduce stress and fatigue. After the expedition, collected specimens were donated to the INPA Ichthyological Collection at Manaus, Brazil.

Bite performance. In-vivo bite forces were recorded using a customized portable and waterproof force gauge constructed of a LCGD -250 low profile miniature load cell (range $=0-250 \mathrm{lbs}$ ) and a DP7600 digital high-speed load/strain meter $(500 \mathrm{~Hz}$ sampling rate) (www.omega.com). This species readily performed multiple defensive bites with the transducer placed between the tips of the jaws. After each bite, peak force was recorded and the force gauge was removed from the jaws and tared before the next attempt. After bite force trials, fish weight (g) and total length (mm) were measured, and the fish was either euthanized in an ice bath for later anatomical dissections or released alive. All bite performance experiments with live wild caught piranhas comply with the guidelines of the Western Kentucky University

Institutional Animal Care and Use Committee.

Jaw functional morphology. In the field, individual S. rhombeus were sacrificed and dissected to investigate the morphology of the lower jaw mechanism. For each fish, the main subdivisions of the adductor mandibulae (A1, A2, and A3), the major jaw closing muscles, were excised and weighed with an Ohaus $\mathrm{HH}-320$ digital scale to the nearest $0.1 \mathrm{~g}$. Adductor mandibulae subdivisions were carefully investigated for their origins, insertions, and lines of action. Musculoskeletal anatomy follows the nomenclature conventions of Machado-Allison ${ }^{16}$. For six individual fish covering a range of body sizes (210-368 mm TL), digital photographs of the dissected jaw anatomy were taken from the fish's right side with a scale bar in frame. Photographs were analyzed using ImageJ64 (http://imagej.nih.gov/ij) to determine landmark coordinates of adductor muscle insertions and origins and lower jaw dimensions. Morphometric data were then analyzed with MandibLever v3. $5^{30}$. MandibLever calculates static and dynamic bite forces from jaw lever mechanics, non-linear lengthtension muscle contractile properties using the Hill equation, and estimates of adductor muscle physiological cross-sectional area. ANCOVA was then used to compare the allometries of simulation results and in-vivo bite performance with body size as the covariate. A non-significant interaction term indicated parallel slopes between these two relationships. Subsequently, the ANCOVA model was rerun without the interaction to examine if a significant difference existed between the predicted anterior bite forces generated by MandibLever and the empirically measured in-vivo bite forces recorded in the wild.

\section{Scaling analyses. We summarized the mean and standard deviations of bite} performance for each individual (SI Table 1). The peak force $(\mathrm{N})$ recorded for each individual was used as a conservative estimate of the maximum bite performance for that individual. To scale bite forces in S. rhombeus, maximum bite force was regressed against total length (TL). The null hypothesis was isometry (i.e. slope $=2.0$ ) in maximum bite force relative to body size. A second scaling relationship was also developed to examine the growth rate of the $5^{\text {th }}$ premaxillary tooth in S. rhombeus. The null hypothesis for isometric growth in tooth length was an expected slope of 1.0. The regression equation for this allometric relationship was then used as a proxy to back-calculate an estimated body size for $M$. paranensis using the homologous length for its $5^{\text {th }}$ premaxillary fossil tooth. Allometric relationships were developed using standard least square regression models. All data were $\log _{10}$ transformed and analyzed using JMP v5 by SAS Institute (2002) statistical software program.

Reconstructing the bite of megapiranha paranensis. We have generated hypothetical estimates of the body size and maximum bite forces of $M$. paranensis by extrapolating predictions from allometric relationships of its close living relative,
Serrasalmus rhombeus. S. rhombeus is the largest carnivorous species of piranha in the Amazon River basin growing to over $3 \mathrm{~kg}$. From the morphological phylogeny, the monotypic $M$. paranensis is nested between Catoprion and the higher monophyletic clade of Pygopristis, Serrasalmus, and Pygocentrus ${ }^{17}$ (SI Fig. 1). Thus, we chose S. rhombeus as a suitable surrogate piranha morphotype with which to reconstruct $M$. paranensis bite forces based on their grossly similar carnivorous tooth morphologies and close phylogenetic relationship. To reconstruct hypothetical bite forces in $M$. paranensis, we used two estimates of body size: the smaller $710 \mathrm{~mm} \mathrm{TL}$, based on the scaling analysis of tooth growth rates in S. rhombeus in this study (Fig. 2), and the larger $1280 \mathrm{~mm}$ TL estimate ${ }^{17}$. From these two body sizes, we calculated lower and upper bounds for maximum bite forces using the regression equation generated from the scaling relationship of S. rhombeus' in-vivo bite forces (Fig. 1A).

Bite simulations. To investigate the effects of tooth shape on fracturing vertebrate bone, bite simulations were conducted using a metal replica of the M. paranensis fossil teeth and premaxilla. The full-scale dental-grade model was forged from bronze-alloy by Master Craftsman Studios. Metal alloy replicas of fossil teeth provide sufficient yield strength and hardness to perform as an enameled tooth analog for testing bite indentations ${ }^{4,26}$. Simulation trials penetrated ecologically relevant bony prey materials of varying thickness (e.g. cortical layer of freshly thawed bovine femur, turtle carapace, and dermal fish scales). Indentation trials examined normal loading of the Megapiranha replica puncturing into the material. The bony materials were secured in a United Testing Systems SSTM-10 KN universal loading frame and indented with the replica at a rate of $1 \mathrm{mms}^{-1}$ with a displacement sampling rate of $20 \mathrm{~Hz}$. Each trial tested the range of predicted bite forces from this study (e.g. 1240-4749 N) (Fig 3).

FEA of serrasalmid tooth shape. For M. paranensis fossil tooth comparisons to extant serrasalmid species, homologous premaxillary teeth were isolated from preserved specimens from the Field Museum of Natural History Fish Collection for Pygocentrus nattereri (FMNH 108184) and Piaractus brachypomus (FMNH 110198). Three dimensional tooth models were generated for each species using a Next Engine $360^{\circ}$ Digital Laser Scanner. Individual teeth were then isolated from laser scans using MeshLab (v1.3.1 Visual Computing Lab - ISTI - CNR), which was also used to fill holes and simplify the meshes. Tooth meshes were then uploaded into Amira (v5.2.2 Visage Imaging), where they were converted from shells to solids. Solid models were imported into Marc Mentat (2010.1.0 MSC Software Corporation) for analysis, and elements were set to be solid tetras. There has been little work done on nonmammalian tooth materials properties, so we used an average of the Young's Moduli found for shark species $\left(7.05 \text { e } 08 \mathrm{~N} / \mathrm{m}^{2}\right)^{31}$ and a Poisson's ratio of 0.3 , a standard for mineralized materials. Nodes at the base of each tooth model, where the tooth would articulate with the underlying bone, were held motionless while the rest of the model was allowed to move and rotate without constraint. Each model was subjected to two different types of loading at both the maximum and minimum predicted bite force for Megapiranha paranensis. To compare between teeth of different sizes, we scaled applied forces such that the ratio of force to approximate surface area would be similar between treatments ${ }^{32}$. For the first treatment, to mimic the point at which the tooth first interacts with a hard surface, we loaded a small area at the very tip of the tooth cusp. In the second treatment, to simulate the forces exerted when the tooth has been driven into the prey, we loaded each tooth to a depth approximately equal to one third of the tooth height. This depth was based on penetration distance taken during the indentation trials. We measured the Von Mises stresses distributed in each model, as a proxy for structural failure; higher Von Mises values means a greater likelihood of structural failure. Stress distribution patterns in each tooth were also compared across the different treatments. To measure Total Strain Energy, tooth models were imported into COMSOL Multiphysics (version 4.3.0.151) and subjected to the same load treatments. The force used for each tooth was scaled so that the ratio of applied force to approximate volume was equivalent for comparison between models ${ }^{32}$.

Mega-predator comparisons. Bite Force Quotients (BFQ) were calculated following the method of Wroe et al. ${ }^{25}$. Briefly, maximum anterior bite forces $(\mathrm{N})$ and body sizes (g) for each of seven additional predatory species were gleaned from the literature (SI Table 2). Where possible, small and large bite force estimates for each species were included along with the low and high range of bite force measurements for $S$. rhombeus and estimates for $M$. paranensis from this study for a total of sixteen data points. Data were then $\log _{10}$ transformed and all species bite forces were regressed against body size to generate a Mega-predator linear regression equation $\left(\log _{10}\right.$ $($ Predicted BF $\left.)=0.59 \log _{10}(\mathrm{~g})+0.16 ; \mathrm{r}^{2}=0.84, \mathrm{P}<0.0001\right)$. From this Megapredator linear regression 'predicted' bite forces for each species body size were calculated, and the size corrected BFQ for each species was generated with the following equation: (Anterior Bite Force/Predicted Bite Force) * 100.

1. Purnell, M. A. Chapter 12: Scenarios, selection and the ecology of early vertebrates. In Major Events in Early Vertebrate Evolution. Ed. Per Erik Ahlberg, Publishers Taylor and Francis: London and New York (2001).

2. Anderson, P. S. L. \& Westneat, M. W. Feeding mechanics and bite force modeling of the skull of Dunkleosteus terrelli, an ancient apex predator. Biol. Lett. 3, 77-80 (2007).

3. Grubich, J. R., Rice, A. N. \& Westneat, M. W. Functional morphology and bite mechanics in the great barracuda. Sphyraena barracuda. Zoology 111, 16-29 (2008). 
4. Gignac, P. M., Makovicky, P. J., Erickson, G. M. \& Walsh, R. P. A description of Deinonychus antirrhopus bite marks and estimates of bite force using tooth indentation simulations. J. Vert. Paleo. 30(4), 1169-1177 (2010).

5. Wroe, S. et al. Three-dimensional computer analysis of white shark jaw mechanics: how hard can a great white bite? J. Zool. 276, 336-342 (2008).

6. Davis, J. L., Santana, S. E., Dumont, E. R. \& Grosse, I. R. Predicting bite force in mammals: two-dimensional versus three-dimensional lever models. J. Exp. Biol. 213, 1844-1851 (2010).

7. Huber, D. R., Eason, T. G., Hueter, R. E. \& Motta, P. J. Analysis of bite force and mechanical design in the feeding mechanism of the durophagous horn shark, Heterodontus francisci. J. Exp. Biol. 208, 3553-3571 (2005).

8. Erickson, G. M., Lappin, A. K. \& Vliet, K. A. The ontogeny of bite-force performance in American alligators (Alligator mississippiensis). J. Zool. Lond. 260 317-327 (2003).

9. Mara, K. R., Motta, P. J. \& Huber, D. R. Bite force and performance in the durophagous bonnethead shark, Sphyrna tiburo. J. Exp. Zool. 311A, 1-11 (2009).

10. Erickson, G. M., Lappin, A. K., Parker, T. \& Vliet, K. A. Comparison of bite force performance between long term captive and wild American alligators (Alligator mississippiensis). J. Zool. Lond. 262, 21-28 (2004).

11. Goulding, M. The Fishes and the Forest: Explorations in Amazonian Natural History. Univ. California Press, Los Angeles (1980).

12. Machado-Allison, A. \& Garcia, C. Food habits and morphological changes during ontogeny in three serrasalmin fish species of the Venezuelan floodplains. Copeia (1), 193-195 (1986).

13. Nico, L. G. \& Taphorn, D. C. Food habits of piranhas in the lowland Llanos of Venezuela. Biotropica 20(4), 311-321 (1988).

14. Orti, G., Sivasundar, A., Dietz, K. \& Jégu, M. Phylogeny of the Serrasalmidae (Characiformes) based on mitochondrial DNA sequences. Gen. \& Mol. Biol. 31, 343 (2008).

15. Jégu, M. Checklist of the Freshwater Fishes of South and Central America. Reis, R. E., Kullander, S. O., Ferraris, Jr. C. J. Eds. (EDIPUCRS, Brasil) pp. 182-196 (2003).

16. Machado-Allison, A. Studies on the systematics of the subfamily Serrasalminae (Pisces-Characidae). Ph.D. Thesis, George Washington University, pp 267 (1982).

17. Cione, A. L., Dahdul, W. M., Lundberg, J. G. \& Machado-Allison, A. Megapiranha paranensis, a new genus and species of Serrasalmidae (Characiformes, Teleostei) from the upper Miocene of Argentina. J. Vert. Paleo. 29(2), 350-358 (2009).

18. Hoorn, C. et al. Amazonia through time: Andean uplift, climate change, landscape evolution, and biodiversity. Science 330, 927-931 (2010)

19. de Lapparent de Broin, F., Bocquentin, J. \& Negri, F. R. Gigantic turtles (Pleurodira, Podocnemididae) from the late Miocene-early Pliocene of southwestern Amazon. Bull. Inst. Fr. Etu. And. 22(3), 657-670 (1993).

20. Huber, D. R., Weggelaar, C. L. \& Motta, P. J. Scaling of bite force in the blacktip shark. Carcharhinus limbatus. Zoology 109, 109-119 (2006).

21. Huber, D. R., Dean, M. N. \& Summers, A. P. Hard prey, soft jaws and the ontogeny of feeding mechanics in the spotted ratfish, Hydrolagus colliei. J. R. Soc. Interface 5 941-953 (2008).

22. Kolmann, M. A. \& Huber, D. R. Scaling of feeding biomechanics in the horn shark Heterodontus francisci: ontogenetic constraints on durophagy. Zoology 112, 351-361 (2009).

23. Wainwright, P. C., Bellwood, D. R., Westneat, M. W., Grubich, J. R. \& Hoey, A. S. A functional morphospace for the skull of labrid fishes: patterns of diversity in a complex biomechanical system. Biol Linn J. Soc. 82, 1-25 (2004).

24. Westneat, M. W. Evolution of levers and linkages in the feeding mechanisms of fishes. Integr. Comp. Biol. 44(5), 378-391 (2004).

25. Wroe, S., McHenry, C. \& Thomason, J. Bite Club: comparative bite force in big biting mammals and the prediction of predatory behavior in fossil taxa. Proc. Roy. Soc. Lond. Ser. B 272, 619-625 (2005).
26. Erickson, G. M. et al. Bite-force estimation for Tyrannosaurus rex from toothmarked bones. Nature 382, 706-707 (1996).

27. Mol, J. H. Attacks on humans by the piranha Serrasalmus rhombeus in Suriname. Stud. Neotrop. Fauna \& Envir. 41(3), 189-195 (2006).

28. Whitenack, L. B., Simkins, D. C. Jr. \& Motta, P. J. Biology Meets Engineering: The structural mechanics of fossil and extant shark teeth. J. Morph. 272, 169-179 (2011).

29. Anderson, P. S. L., Gill, P. G. \& Rayfield, E. J. Modeling the effects of cingula structure on strain patterns and potential fracture in tooth enamel. J. Morph. 272, 50-65 (2011).

30. Westneat, M. W. A biomechanical model of muscle force, motion, and power output in the lower jaws of fishes. J. Theor. Biol. 223, 269-281 (2003).

31. Whitenack, L. B., Simkins, D. C., Motta, P. J., Hirai, M. \& Kumar, A. Young's modulus and hardness of shark tooth biomaterials. Arch. Oral. Biol. 55, 203-209 (2010).

32. Dumont, E. R., Grosse, I. R. \& Slater, G. J. Requirements for comparing the performance of finite element models of biological structures. J. Theor. Biol. 256, 96-103 (2009).

\section{Acknowledgements}

We would like to thank our Brazilian guides for their service, and the Kararo and Arara Tribes of the Xingu River for their hospitality. The expedition was funded by a National Geographic Expeditions Council Grant (\#EC0463-10) to J.R. Grubich. Research support was provided by National Geographic Development Funds x20469-03-1008 \& a WKU Faculty Scholarship Award (\#10-7072) to S. Huskey, as well as a Field Museum of Natural History Collection Research Grant and WKU Travel Grant to J.R. Grubich.

\section{Author contributions}

JRG was responsible for manuscript composition. SH and JRG were responsible for piranha jaw functional morphology interpretation as well as bite performance and bite simulation protocols and analyses. JRG calculated serrasalmid allometry, MandibLever v3.5 results, and BFQ calculations, as well as 3D digital reconstruction of serrasalmid premaxillary teeth. $\mathrm{SH}$ was responsible for bite gauge construction and material tester access, as well as skeleton construction. SC developed the Finite Element Analysis of premaxillary teeth using 3D digital tooth vector algorithms and generated Von Mises Stress and Total Strain Energy data. GO was responsible for species identification and data collection, as well as phylogenetic justification and analysis of serrasalmid relationships. JP procured INPA fish collection permits, acted as liaison with indigenous tribes, and assisted in data collection and interpretation.

\section{Additional information}

Supplementary information accompanies this paper at http://www.nature.com/ scientificreports

Competing financial interests: The authors declare no competing financial interests.

License: This work is licensed under a Creative Commons Attribution-NonCommercial-NoDerivs 3.0 Unported License. To view a copy of this license, visit http://creativecommons.org/licenses/by-nc-nd/3.0/

How to cite this article: Grubich, J.R., Huskey, S., Crofts, S., Orti, G. \& Porto, J. Mega-Bites: Extreme jaw forces of living and extinct piranhas (Serrasalmidae). Sci. Rep. 2, 1009; DOI:10.1038/srep01009 (2012) 